\title{
Biochemical and Immunocytological Localization of Molluscan Small Cardioactive Peptides in the Nervous System of Aplysia californica ${ }^{1}$
}

\author{
P. E. LlOYd, ${ }^{2}$ A. C. MAHON, ${ }^{*}$ I. KUPFERMANN, J. L. COHEN, R. H. SCHELleR, ${ }^{*}$ and K. R. WEISS
}

Center for Neurobiology and Behavior, Columbia University College of Physicians and Surgeons, The New York Psychiatric Institute, New York, New York 10032 and *Department of Biological Sciences, Stanford University, Stanford, California 94305

\begin{abstract}
High pressure liquid chromatography (HPLC) followed by bioassay on isolated snail hearts were used to locate two related peptides, termed small cardioactive peptides $A$ and $B\left(S C P_{A}\right.$ and $\left.S C P_{B}\right)$ in each of the central ganglia of Aplysia. The peptides are most concentrated in the buccal ganglia, the ganglia involved in the control of feeding movements. Immunocytology with antisera raised to conjugated $\mathrm{SCP}_{\mathrm{B}}$ stained three groups of neurons in the buccal ganglia. One group consisted of relatively small neurons that were tightly clustered. The second group was comprised of larger neurons that were more scattered. The third group was made up of several neurons including the two largest in the ganglia, identified cells B1 and B2. B1 and B2 and other neurons in this group innervate the gut by way of the esophageal nerve. HPLC-bioassay of single, individually dissected B1 or B2 neurons demonstrated that the two peptides are present in a single cell. For B2, but not B1, choline injected into the cell body was converted to the conventional transmitter, acetylcholine. This indicates that, in addition to the two peptides, $\mathrm{B2}$ also contains choline acetyltransferase, and raises the possibility that acetylcholine and the SCPs may act as cotransmitters in B2. Strong immunocytological staining of fibers and varicosities was observed in the neuropilar region of the cerebral, pleural, pedal, and abdominal ganglia. In addition to the buccal ganglia, immunoreactive neurons were observed in all of the other central ganglia. The high concentration of the SCPs and the relatively large number of immunoreactive neurons in the buccal ganglion suggest a particularly important role of these peptides specifically in feeding behavior. However, the widespread occurrence of the SCPs in fibers and neuronal cell bodies throughout the nervous system suggests that these peptides also may have additional behavioral functions in Aplysia.
\end{abstract}

In recent years our notions of chemical transmission in the nervous

Received October 5, 1984; Revised December 13, 1984; Accepted December 18, 1984

\footnotetext{
${ }^{1}$ We thank Tom Abrams, Eric Kandel, and John Koester for critically reading the manuscript. This work supported by National Institute of Mental Health Grant MH 367330 to K. R. W. and by grants to R. H. S. from the National Institutes of Health. A. C. M. is a recipient of a National Institutes of Health postdoctoral fellowship. K. R. W. is a recipient of Career Scientist Development Award MH 00304.

${ }^{2}$ To whom correspondence should be directed, at his present address: Department of Pharmacological and Physiological Sciences, The University of Chicago, Chicago, IL 60637.
}

system have been greatly altered by the finding that, in addition to a few conventional neurotransmitters, a number of neuropeptides can serve as modulators and transmitters (Krieger, 1983). Currently, there are a number of model systems in vertebrates which permit the study of the cell biology and function of peptidergic transmission (e.g., Lundberg, 1981; Jan and Jan, 1982). Peptidergic neurons have also been described in several invertebrates, particularly two groups: arthropods (Eckert et al., 1981; Bishop and O'Shea, 1982; Adams and O'Shea, 1983; El-Salhy et al., 1983; Siwicki and Kravitz, 1983) and gastropod molluscs (Chiu and Strumwasser, 1981; Schot et al., 1981; Osborne et al., 1982; Cottrell et al., 1983; McAllister et al., 1983; Kreiner et al., 1984; Vigna et al., 1984). These animals offer the advantage that their nervous systems are comprised of identified neurons that can be related to well defined sensory and motor functions. Thus, invertebrates otter the opportunity to study in detail the role of peptidergic neurons in behavior. In addition, many invertebrate nervous systems are comprised of a relatively small number of neurons. This greatly facilitates obtaining a global picture of the function of given peptides throughout the whole nervous system and facilitates the approach to problems that are difficult to study in more complex systems.

Previous studies have shown that the nervous system and other tissues of several molluscs contain a number of peptides that have powerful cardioexcitatory actions (Lloyd, 1982; Greenberg et al., 1983). Two such peptides, termed small cardioactive peptides $A$ and $\mathrm{B}\left(\mathrm{SCP}_{\mathrm{A}}\right)$ and $\left.\mathrm{SCP}_{\mathrm{B}}\right)$, are present in large quantities in the gut and nervous system of $\Lambda$ plysia. $\mathrm{SCP}_{\mathrm{B}}$ has been purified from the nervous system of Aplysia (Morris et al., 1982) and has been sequenced. Recently, the structure of $\mathrm{SCP}_{\mathrm{A}}$, a peptide closely related to $\mathrm{SCP}_{\mathrm{B}}$, has been determined (Lloyd et al., 1984b), and the sequence of a precursor polypeptide containing both $\mathrm{SCP}_{\mathrm{A}}$ and $\mathrm{SCP}_{B}$ has been inferred from the nucleotide sequence of a CDNA clone (Mahon et al., 1985)

In this paper we have combined biochemical-bioassay techniques with immunocytological procedures to determine the localization and distribution of the SCPs in the nervous system of Aplysia. We report that $S C P_{A}$ and $S C P_{B}$ are present in all of the major central ganglia of Aplysia and are characteristically. concentrated in fibers and varicosities in the neuropil of each ganglion. Immunoreactive neurons are found most commonly in the buccal and cerebral ganglia, two ganglia that have been implicated in the control of feeding behavior (Kupfermann, 1974). However, the widespread occurrence of the SCPs in fibers and neuronal cell bodies throughout the nervous system suggests that these peptides may have multiple behavioral functions. Indeed, the SCPS appear to have a wide range of actions in Aplysia. To date, these peptides have been shown to enhance feeding muscle contractions (Lloyd et al., 1984a), stimulate cardiac activity (Lloyd et al., 1985), and facilitate the synaptic connections between sensory and motor neurons (Abrams et al., 1984). The combination of their wide distribution and range of activity suggests 
TABLE I

Levels of the SCPS in the central nervous system of Aplysia

\begin{tabular}{lcr}
\hline \multicolumn{1}{c}{ Tissue $^{a}$} & $\mathrm{SCP}_{\mathrm{A}}$ & $\mathrm{SCP}_{\mathrm{B}}$ \\
\hline & pmol/gm of & wet \\
& \multicolumn{2}{c}{ weight } \\
Abdominal ganglia & 747 & 467 \\
Buccal ganglia & 4500 & 3338 \\
Cerebral ganglia & 672 & 354 \\
Pedal ganglia & $43 /$ & 510 \\
Pleural ganglia & 473 & 486 \\
Abdominal-plet ural connective & 22 & 25 \\
Cerebral-buccal connective & $<2$ & $<2$ \\
Esophageal nerve & 517 & 728 \\
\hline
\end{tabular}

${ }^{2}$ Tissue was pooled from four medium-sized ( 180 to $200 \mathrm{gm}$ ) animals
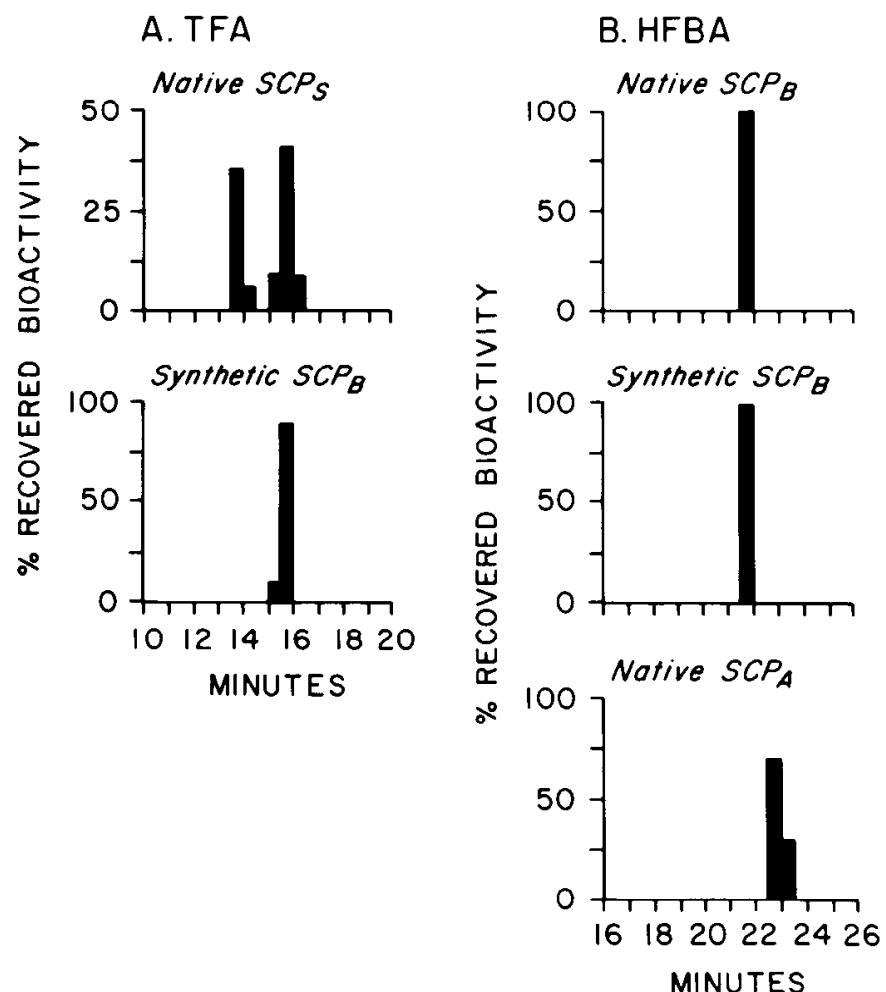

Figure 1. HPLC of synthetic $\mathrm{SCP}_{\mathrm{B}}$ and native SCPs from a crude extract of the buccal ganglion from $A$. californica. $A$, Chromatography of native SCPs compared to that of synthetic $\mathrm{SCP}_{\mathrm{B}}$. In both cases, aliquots of each 30-sec sample were dried, and the position of active substances was located 'วy their activity on the isolated snail heart. The column was developed with a gradient of $\mathrm{CH}_{3} \mathrm{CN}$ from 25 to $50 \%$ at $1 \mathrm{ml}$ and $1 \% / \mathrm{min}$. The counter-ion was $0.01 \mathrm{M}$ TFA. Note that native $\mathrm{SCP}_{\mathrm{B}}$ elutes later than $\mathrm{SCP}_{\mathrm{A}}$ and in the same position as synthetic $\mathrm{SCP}_{\mathrm{B}}$. $B$, Chromatography of native $\mathrm{SCP}_{\mathrm{A}}$ and $\mathrm{SCP}_{\mathrm{B}}$ (taken from the run shown in $A$ ) and synthetic $\mathrm{SCP}_{\mathrm{B}}$. The gradient was the same as described above, but the TFA was replaced with $0.01 \mathrm{M} \mathrm{HFBA}$ as the counter-ion. Note that the order of elution of the SCPs has reversed, and native and synthetic $\mathrm{SCP}_{\mathrm{B}}$ again have precisely the same retention times.

that the SCPS are important central and peripheral regulators in Aplysia.

\section{Materials and Methods}

\section{Dissection, extraction, and bioassay of neurons}

Ganglia were dissccted and pinned in dishes containing artificial seawater (ASW), and individual cells were removed using a modification of the method of Ono and McCaman (1980). In brief, the ASW was replaced with several washes of a solution of $50 \%$ propylene glycol $-50 \%$ ASW at $0^{\circ} \mathrm{C}$, and the connective tissue was cut away from the surface of the ganglia. Individual neuronal somata were manually dissected and removed from the solution with fine forceps and placed in glass tubes containing $50 \mu \mathrm{l}$ of $0.1 \mathrm{M}$ acetic acid by means of a glass microprobe. The tube was immediately immersed in boiling water for $5 \mathrm{~min}$ and then lyophilized. The resulting crude extract was taken up in snail saline, and the activity present in it was quantified on the isolated Helix heart (Lloyd, 1978). This preparation responds with an increase in beat amplitude to the injection of as little as $10 \mathrm{fmol}$ of $S C P_{A}$ or $\mathrm{SCP}_{\mathrm{B}}$. However, in samples in which measured quantities of synthetic $\mathrm{SCP}_{\mathrm{A}}$ and $\mathrm{SCP}_{\mathrm{B}}$ were added to neurons known not to contain cardioactive substances, the minimum quantity of the peptides that could be detected above background was $40 \mathrm{fmol}$.

Individual B1 and B2 neurons were identified on the basis of their size and characteristic position in the ganglion (Gardner, 1971). Neuron B2 was located closest to the esophageal nerve, whereas B1 was more lateral. Ganglia in which the neurons could not be unequivocally identified were not used in experiments that required differentiating between the neurons.

\section{Reverse phase high pressure liquid chromatography (RP-HPLC)}

This procedure was carried out on a DuPont $\mathrm{C}-8$ column developed with a gradient from $25 \% \mathrm{CH}_{3} \mathrm{CN}, 75 \% \mathrm{H}_{2} \mathrm{O}$ to $50 \% \mathrm{CH}_{3} \mathrm{CN}, 50 \% \mathrm{H}_{2} \mathrm{O}$ at $1 \mathrm{ml}$ and $1 \% / \mathrm{min}$. Either $0.01 \mathrm{M}$ trifluoroacetic acid (TFA) (Pierce) or $0.01 \mathrm{M}$ heptafluorobutyric acid (HFBA) (Pierce) (Bennett et al., 1980) was included as volatile modifier in both the $\mathrm{CH}_{3} \mathrm{CN}$ and $\mathrm{H}_{2} \mathrm{O}$. Fractions from these columns were lyophilized and assayed on the isolated snail heart. Weighed portions of the tissues were extracted in an at least 10-fold excess volume of $0.1 \mathrm{M}$ acetic acid. This sample was placed in a boiling water bath for $10 \mathrm{~min}$, homogenized, and centrifuged at $20,000 \times g$ for $10 \mathrm{~min}$, and the resulting supernatant was lyophilized and taken up in the starting buffer for RP-HPLC. To improve the yield for single neurons, they were dissected as described above and added to $10 \mathrm{mg}$ pieces of Aplysia ventricle which acted as a carrier. The sample was processed as described above for tissue extracts. In every experiment, a 10-mg ventricle sample was also processed without added neurons and never showed activity in the SCP region of the RP-HPLC. Pooled neurons were processed in a manner similar to that of the tissue extracts, except that the centrifugation step was replaced with filtration through 0.45- $\mu \mathrm{m}$ membranes (Millipore).

\section{Choline acetyltransferase (CAT) assay}

$\left[{ }^{3} \mathrm{H}\right]$ Choline with a specific activity of $2.34 \mathrm{Ci} / \mathrm{mmol}$ (New England Nuclear) was prepared for injections by concentrating in a vacuum centrifuge. Identified neurons were injected with $\left[{ }^{3} \mathrm{H}\right]$ choline by pressure through a micropipette (Eisenstadt et al., 1973; Koike et al., 1974). The ganglion containing the injected neuron was then incubated for $1 \mathrm{hr}$ at $15^{\circ} \mathrm{C}$ in ASW supplemented with cold choline, amino acids, vitamins, and glucose. Following incubation, the neuronal part of the ganglion was homogenized in $0.5 \mathrm{ml}$ of ice-cold acetone $/ 1 \mathrm{M}$ formic acid $(85 / 15, \mathrm{v} / \mathrm{v})$. Radioactive compounds present in the homogenates were separated by high voltage paper electrophoresis (Giller and Schwartz, 1971) and counted in a liquid scintillation counter. Under our conditions, $1500 \mathrm{cpm}$ equaled $1 \mathrm{pmol}$ of labeled material.

\section{Immunization}

Immunization was done according to the techniques described by Mahon et al. (1985). In brief, the water-soluble carbodimide, 1-ethyl-3-(3-dimethylamino-propyl)carbodiimide (EDC) was used to couple $S C P_{B}$ and bovine serum albumin (BSA). One milligram of $\mathrm{SCP}_{\mathrm{B}}(0.9 \mu \mathrm{mol}$, Peninsula Biochemicals) and $5 \mathrm{mg}$ of highly purified BSA $(0.07 \mu \mathrm{mol}$, Pentex $)$ were dissolved in $3 \mathrm{ml}$ of water. One milliliter of $3.5 \mathrm{mg}$ of EDC/ml was added and the mixture was incubated for $18 \mathrm{hr}$ at room temperature. Four milliliters of $0.05 \mathrm{M}$ hydroxylamine hydrochloride, $\mathrm{pH} 9.5$. were added and the mixture was incuated a further $5 \mathrm{hr}$, after which the solution was neutralized, divided into $1.5-\mathrm{ml}$ aliquots, and stored at $-20^{\circ} \mathrm{C}$ until used. Two rabbits were injected with 1.5 $\mathrm{ml}$ of an emulsified solution of $\mathrm{SCP}_{\mathrm{B}} \cdot \mathrm{BSA}$ plus Freund's complete adjuvant, and at 2-week intervals the rabbits were injected subcutaneously with $1.5 \mathrm{ml}$ of $\mathrm{SCP}_{\mathrm{B}}-\mathrm{BSA}$ adjuvant. Two antisera prepared in this fashion gave similar results in immunocytology (see below).

\section{Immunocytology of sectioned tissue}

Tissue preparation. Abdominal, buccal, cerebral, pleural, and pedal ganglia were dissected from 50- to 200-gm Aplysia californica. Excess connective tissue was removed under a dissecting microscope and individual ganglia were submerged in O.C.T. (Tissue-Tek II embedding medium). The embedded tissue was frozen rapidly in an isopentane/ $\mathrm{CO}_{2}$ bath and then stored at $-20^{\circ} \mathrm{C}$. The frozen tissue was sliced into $20-\mu \mathrm{m}$ sections, collected onto glass slides, and air dried for $45 \mathrm{~min}$. The sections were fixed at room 


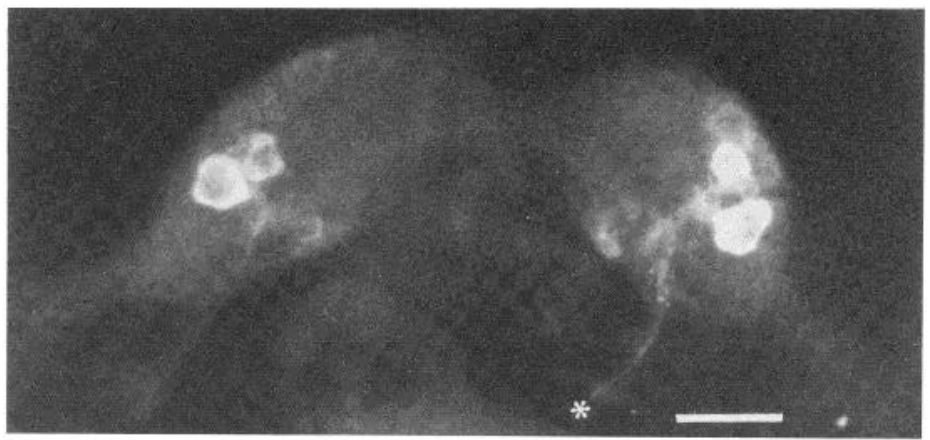

Figure 2. Low power view of whole mount of buccal ganglion of a medium-sized juvenile animal, showing immunoreactive bilateral esophageal cell clusters containing giant identified neurons B1 and B2. The esophageal nerve (asterisk) contains immunoreactive axons from cells in the esophageal cluster. This ganglion is shown at higher gain in Figure 3A. Calibration bar, $100 \mu \mathrm{m}$.
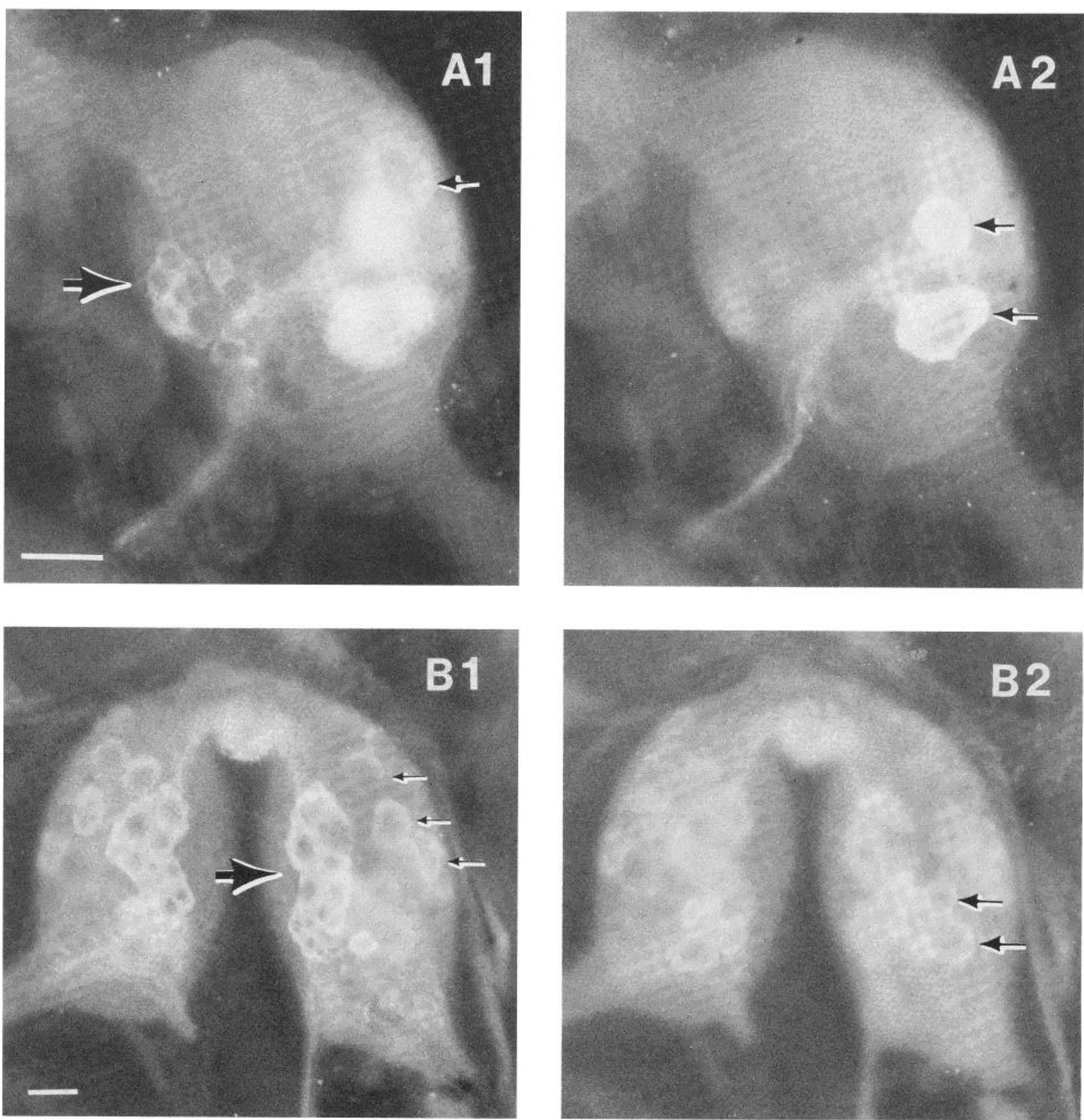

Figure 3. Caudal and rostral focus of whole mount buccal ganglia from a medium-sized juvenile (right hemiganglion shown, $A$ ) and a small juvenile (left and right hemiganglia shown, $B$ ). The rostral focus ( $A 1$ and $B 1$ ) reveals a tight cluster of relatively small cells (large arrows). A1 also shows in focus a single medium-sized cell of the ventral group and out of focus cells of the esophageal cluster. $B 1$ also shows three cells of the ventral cell group (indicated by small arrows in the right hemiganglion). A2 and B2 show the esophageal group with cells B1 and B2 (arrows), and B2 also shows less intensely stained cells of the ventral group. Note that, compared to the larger animal $(A)$, in the small animal $(B)$ the rostral cell group is large relative to the size of neurons B1 and B2. Calibration bars, $50 \mu \mathrm{m}$. 

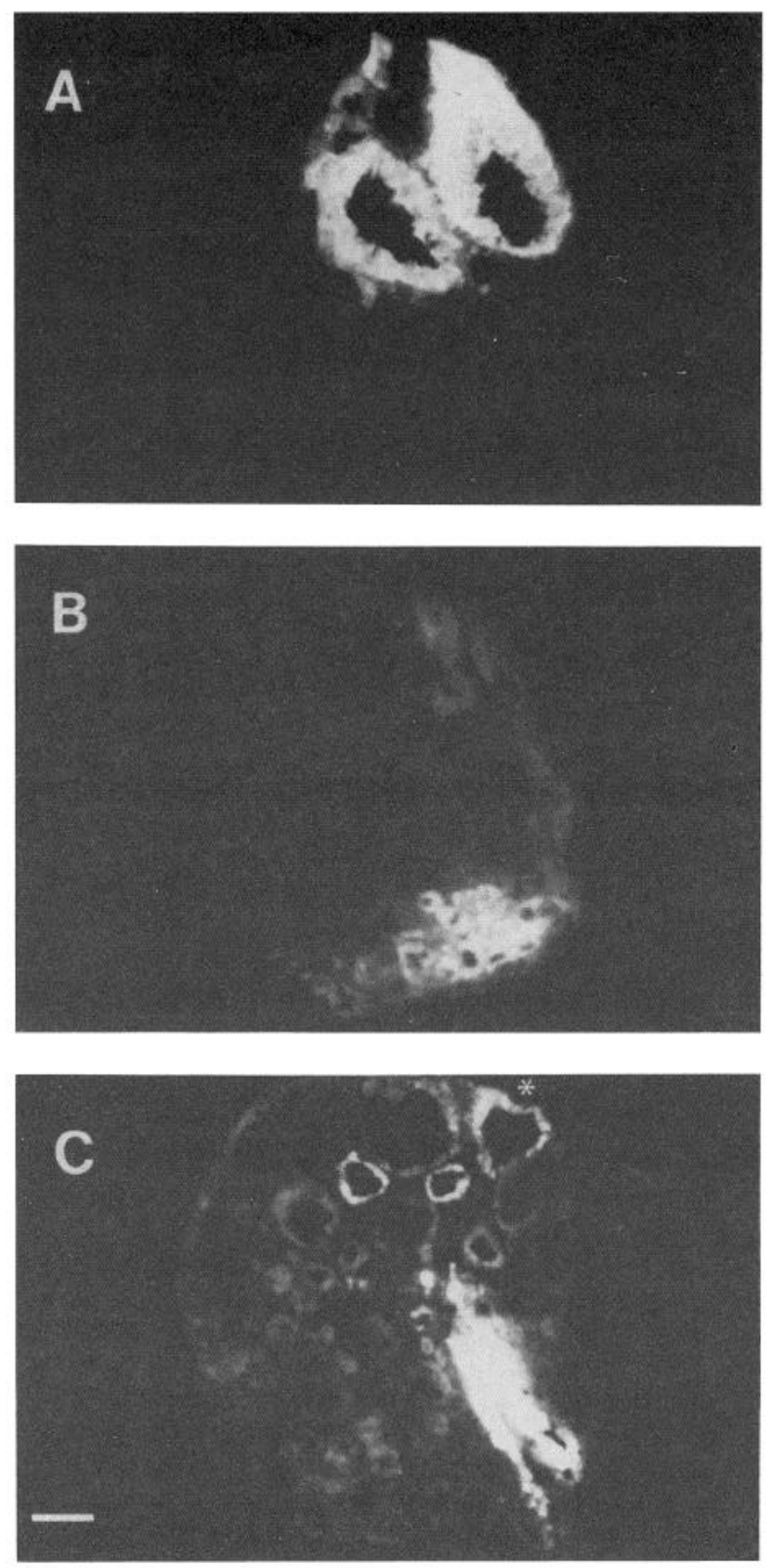

Figure 4. iSCP neurons visualized in $20-\mu \mathrm{m}$ frozen sections from the buccal ganglion of an adult animal. $A, B 1$ and $B 2$ neurons of the esophageal cluster, located on the caudal surface. $B$, Rostral group iSCP neurons, located on the ventral edge of the rostral surface. $C$, Ventral group iSCP neurons. The largest ventral iSCP neuron in the field is marked with an asterisk. The center of the field shows intensely stained axons of B1 and B2 neurons. Calibration bar, $50 \mu \mathrm{m}$.

temperature for $30 \mathrm{~min}$ in $2 \%$ paraformaldehyde and then washed in $0.15 \mathrm{M}$ $\mathrm{NaCl}, 0.02 \mathrm{M}$ phosphate, $\mathrm{pH} 7.5$ (PBS).

Tissue staining. Sectioned tissue was incubated overnight at $4^{\circ} \mathrm{C}$ with 0.3 $\mathrm{ml}$ of primary antibody solution (1/300 dilution of rabbit serum in $0.2 \%$ saponin, $2 \%$ BSA in PBS). Incubation with the secondary antibody solution (1/40 dilution of fluorescein isothiocyanate-conjugated goat anti-rabbit lgG into $0.2 \%$ saponin in PBS) was carried out for $2 \mathrm{hr}$ at $4^{\circ} \mathrm{C}$.

\section{Immunocytology of whole mounts}

Tissue preparation. Whole mounts were prepared from late juvenile Aplysia (5 to $15 \mathrm{~mm}$ in length) obtained from the mariculture facility at the Marine Biological Laboratory (Woods Hole, MA).

To fix whole mounts, the animals were first anesthetized in isotonic $\mathrm{MgCl}_{2} /$ seawater $(1 / 1, v / v)$ and pinned to silicone plastic. The body wall was cut open and any loose connective tissue around the ganglia was cut in order to permit free access of the bathing solutions to all surfaces of the ganglia.

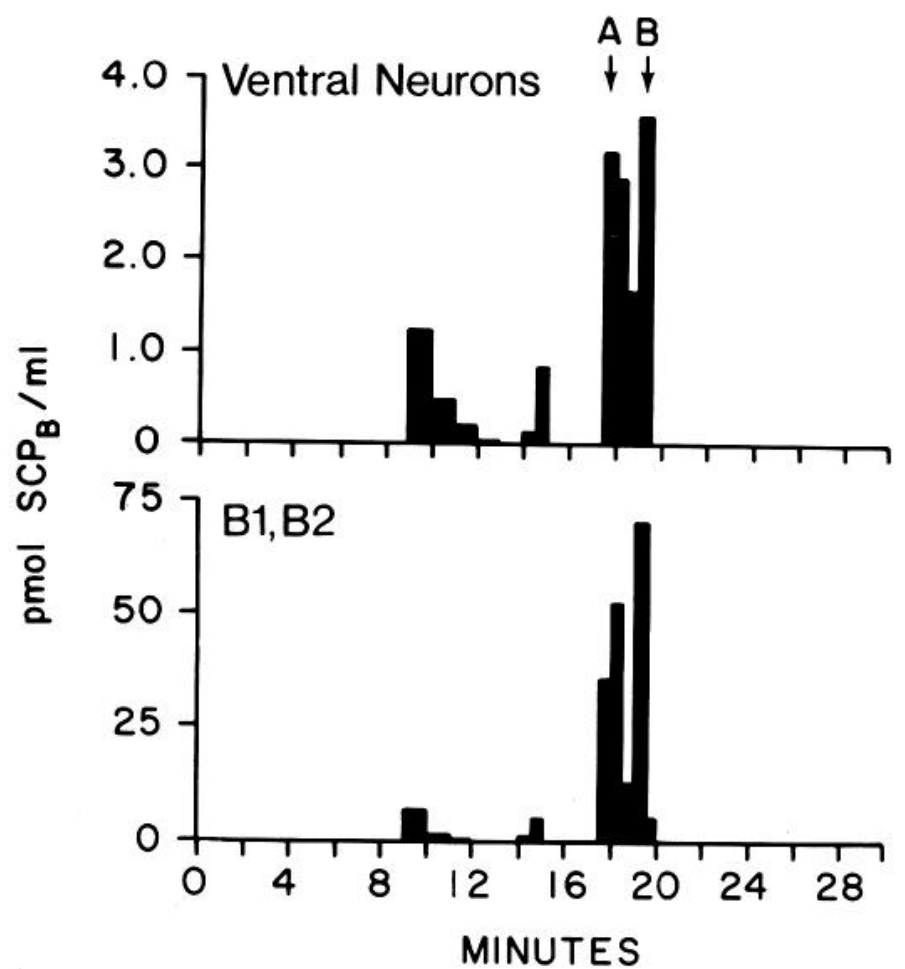

Figure 5. HPLC of cardioactive substances present in extracts of either the four largest ventral neurons or of B1 and B2 neurons pooled from 25 animals. RP-HPLC was carried out with a standard $\mathrm{CH}_{3} \mathrm{CN}$ gradient with 0.01 M TFA as the counter-ion (Fig. 1). Thirty- or $60-\mathrm{sec}$ samples were collected, dried, and bioassayed on isolated snail hearts. The activity present in each sample was standardized against synthetic $\mathrm{SCP}_{\mathrm{B}}$. Note that the major peaks of activity are associated with $\mathrm{SCP}_{\mathrm{A}}$ and $\mathrm{SCP}_{\mathrm{B}}$; there are also several other smaller peaks of activity which elute before the SCPS. The nature of these smaller peaks is currently being investigated. Retention times of the SCPs were delayed relative to those in Figure 1 because a preparative injection loop $(2 \mathrm{ml})$ was used in these runs.

The solution bathing the whole mounts was then replaced by $4 \%$ paraformaldehyde in $0.1 \mathrm{M}$ sodium phosphate buffer ( $\mathrm{pH} 7.4$ ) containing $30 \%$ sucrose. The tissue was left in fixative for $3 \mathrm{hr}$ at $4^{\circ} \mathrm{C}$ and was then washed in three changes of phosphate-buffered sucrose. The whole mounts were left overnight at $4^{\circ} \mathrm{C}$ in the phosphate-buffered sucrose. After a rinse with phosphatebuffered saline $(50 \mathrm{~mm}$ sodium phosphate, $0.9 \% \mathrm{NaCl}$ with 0.03 sodium azide and $0.3 \%$ Triton X-100) (PBS-T), the tissue was dehydrated in a series of 5 -min washes in $50 \%, 70 \%, 80 \%$, and $90 \%$ ethanol, followed by $100 \%$ methanol and rehydration in a descending series of alcohol, with a final incubation in the PBS-T solution. Indirect immunofluorescence methods were based on those of Coons (1958), Goldstein et al. (1984), and McAllister et al. (1983). Whole mounts were preincubated for $0.5 \mathrm{hr}$ in a $1 / 25$ dilution of normal goat serum in PBS-T in order to block nonspecific binding. The tissue was then incubated at $4^{\circ} \mathrm{C}$ with gentle shaking for 2 to 3 days with specific antisera diluted with PBS-T plus 1/25 normal goat serum. This was followed by three rinses in PBS-T plus normal goat serum and incubation for $3 \mathrm{hr}$ at room temperature with a $1 / 25$ dilution of anti-rabbit IgG rhodamine-labeled antibody in goat serum. After washing in PBS-T the ganglia were mounted in $70 \%$ glycerol PBS-T and viewed with a Leitz microscope (filter pack $\mathrm{N}-2$ ) equipped with epifluorescence and photographed with Ektachrome (ASA 400) or Tri-X (ASA 400) film.

\section{Controls for specificity of staining}

A number of controls for antibody specificity were done on whole mounts and sections. Replacement of the primary or secondary fluorescent antibody with normal serum did not result in staining. In addition, staining was blocked by adsorbing the immune serum with $\mathrm{SCP}_{\mathrm{B}}$. For these experiments the immune serum was preincubated with $50 \mathrm{mg} / \mathrm{ml}$ of $S C P_{B}$ for $24 \mathrm{hr}$ at $4^{\circ} \mathrm{C}$ before staining by our standard methods. In sectioned material, additional controls included preincubation with adipokinetic hormone, which did not block staining, and incubation of sectioned ganglia with a rabbit antibody to Lucifer Yellow, which did not label cells. The final and most direct control, 


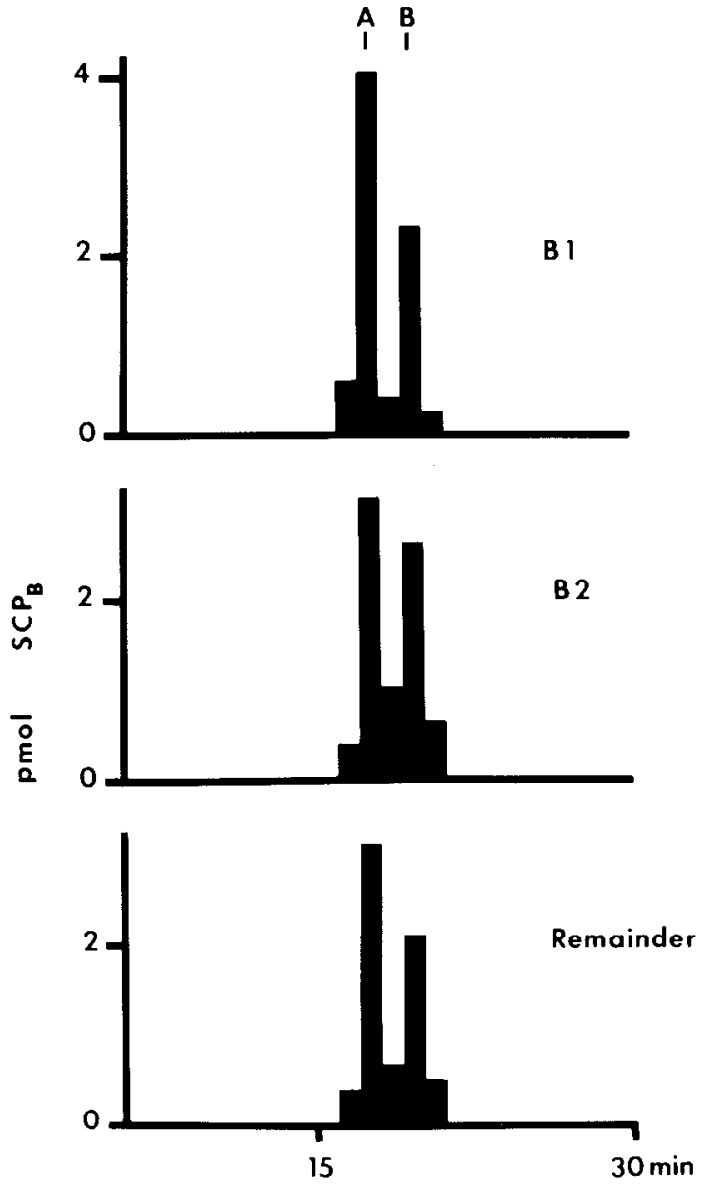

Figure 6. HPLC of cardioactive substances present in extracts of identified single neurons. Individual B1 or B2 neurons or the remainder of the ganglia were added to carrier tissue (ventricle) and extracted. HPLC was carried out with the standard gradient (Fig. 1), $0.01 \mathrm{M}$ TFA as counter-ion, and a preparative injection loop (Fig. 5). Sixty-second samples were collected, dried, and assayed on isolated snail hearts. The activity present in each sample was standardized against synthetic $\mathrm{SCP}_{\mathrm{B}}$. Note that $\mathrm{B} 1$ and $\mathrm{B} 2$ neurons individually contain both SCPS.

as detailed below, consisted of the measurement of the SCPS in selected neurons, using direct bioassay or high pressure liquid chromatography (HPLC) followed by bioassay.

Similar patterns of staining were obtained in whole mounts of six animals and sections from nine animals, using two different antisera we prepared. One whole mount also showed similar staining patterns using an $\mathrm{SCP}_{\mathrm{B}}$ antiserum provided by Dr. Howard Morris (Imperial College, London, England).

\section{Results}

\section{Presence of $\mathrm{SCP}_{A}$ and $S C P_{B}$ in the central ganglia of Aplysia}

All of the central ganglia of Aplysia contained both $\mathrm{SCP}_{\mathrm{A}}$ and $\mathrm{SCP}_{\mathrm{B}}$ as judged by bioassay following RP-HPLC (Table 1). The two peptides were identified as substances that increased the beat amplitude of an isolated snail heart at retention times identical to those of either purified native $\mathrm{SCP}_{\mathrm{A}}$ or purified native and synthetic $S C P_{B}$. The ratio of bioactivity of $\mathrm{SCP}_{B}$ relative to that of $S C P_{A}$ was similar in all of the ganglia. The concentrations of both peptides were also roughly similar in all of the central ganglia with the exception of the buccal ganglia, for which the concentrations were nearly 10 -fold higher than in the other ganglia (Table I).

Since the starting tissue for the original purification of $\mathrm{SCP}_{\mathrm{B}}$ was the ring ganglia (pedal, pleural, and cerebral ganglia) from another species of Aplysia (A. brasiliani), we wished to determine whether synthetic $\mathrm{SCP}_{\mathrm{B}}$ was identical to the peptide present in the buccal

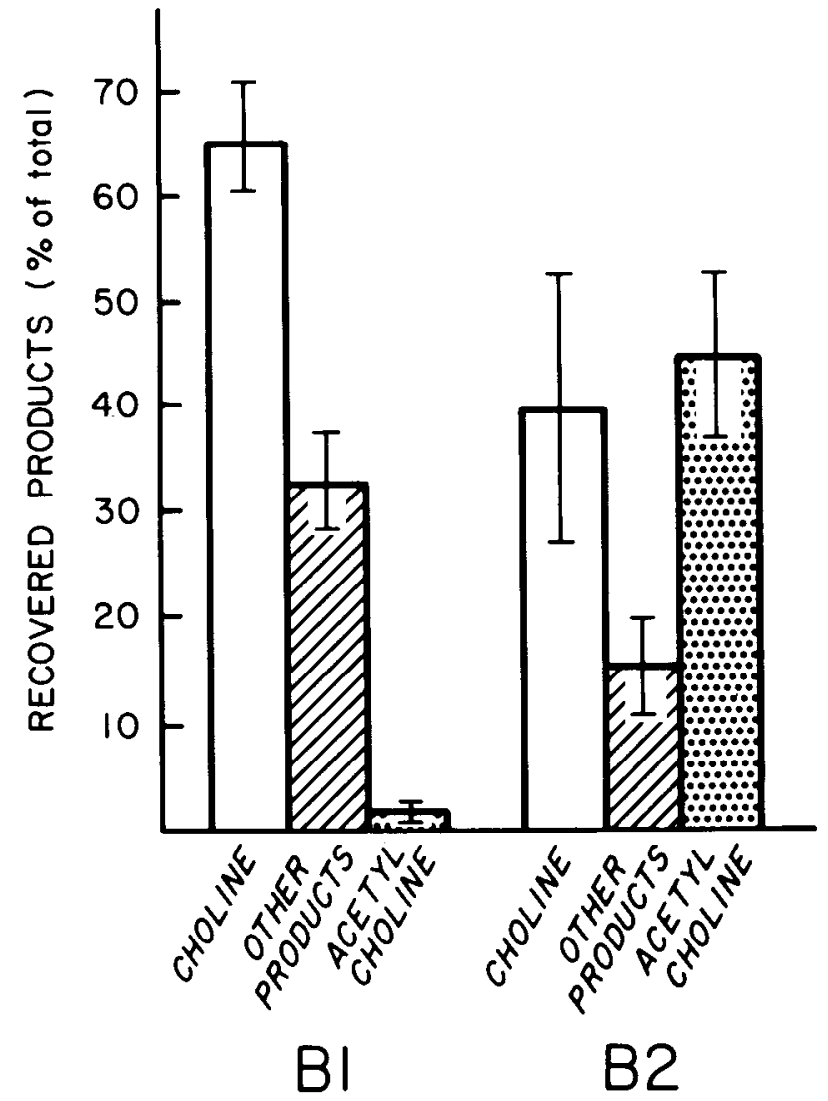

Figure 7. Fate of $\left[{ }^{3} \mathrm{H}\right] \mathrm{choline}$ injected into identified neurons $\mathrm{B} 1$ or $\mathrm{B} 2$. Only trace quantities of CAT activity were present in B1 $(N=3)$, whereas $\mathrm{B} 2(N=5)$ showed this activity at levels comparable to those of known cholinergic neurons (see the text)

ganglia of $A$. californica. Figure 1 shows the results of an experiment in which an extract of the buccal ganglia was chromatographed (RPHPLC) first in the presence of one counter-ion (TFA, Fig. 1A) and aliquots of the resulting samples were assayed on an isolated heart. The remaining portions of the active samples corresponding to $\mathrm{SCP}_{A}$ and $\mathrm{SCP}_{\mathrm{B}}$ were then separately chromatographed in the presence of another counter-ion (HFBA, Fig. 1B). The substitution of HFBA for TFA significantly increased the retention time for both peptides and also reversed the relative retention times for $\mathrm{SCP}_{\mathrm{A}}$ and $\mathrm{SCP}_{\mathrm{B}}$. Synthetic $\mathrm{SCP}_{\mathrm{B}}$ and native $\mathrm{SCP}_{\mathrm{B}}$ from the buccal ganglia of $A$. californica had identical retention times in the presence of either counter-ion. The activity associated with $\mathrm{SCP}_{\mathrm{A}}$ and $\mathrm{SCP}_{\mathrm{B}}$ eluted as single peaks with each counter-ion, suggesting that the activity is due primarily to the presence of one peptide in each peak.

Localization of immunoreactive $\mathrm{SCP}_{B}$ (iSCP $\mathrm{P}_{B}$ ) in the buccal ganglia

\section{Juvenile animals}

In order to localize $\mathrm{SCP}_{\mathrm{B}}$-containing neurons in the buccal ganglion, we used the ganglia from small juvenile animals in which it is possible to obtain staining in whole mounts (Goldstein et al., 1984). The neuropil and fiber tracts of the buccal ganglia showed relatively light $\mathrm{SCP}_{\mathrm{B}}$ staining. There were, however, three distinct groups of bilaterally symmetrical isCP $\mathrm{B}_{\mathrm{B}}$ neurons. One group consisted of a tight cluster of neurons on the caudal surface of the ganglion near the exif of the esophageal nerve and will be referred to as the "esophageal group." A second group of iSCP $\mathrm{P}_{\mathrm{B}}$ neurons in the buccal ganglion consisted of a tight cluster of generally smaller cells located on the rostral surface and will be referred to as the "rostral group." The third group of iSCP $\mathrm{B}_{\mathrm{B}}$ neurons was located on both the rostral and caudal surfaces of the ganglion and was concentrated toward the ventral margin. These will be referred to as the "ventral group." 


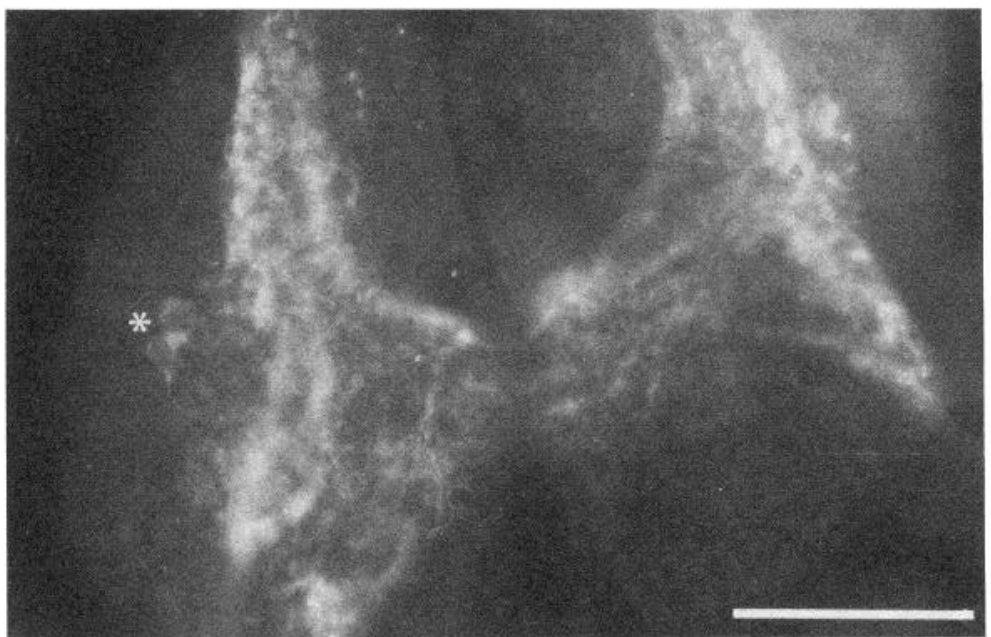

Figure 8. Low power view of a whole mount of the abdominal ganglion of a large juvenile animal viewed from the dorsal surface, with abdominal connectives at the top of the field. A pair of immunoreactive neurons is visible in the left hemiganglion (asterisk) The neuropil, interganglionic commissure, and nerve tracts show strong iSCP ${ }_{\mathrm{B}}$ staining. Calibration bar, $50 \mu \mathrm{m}$.
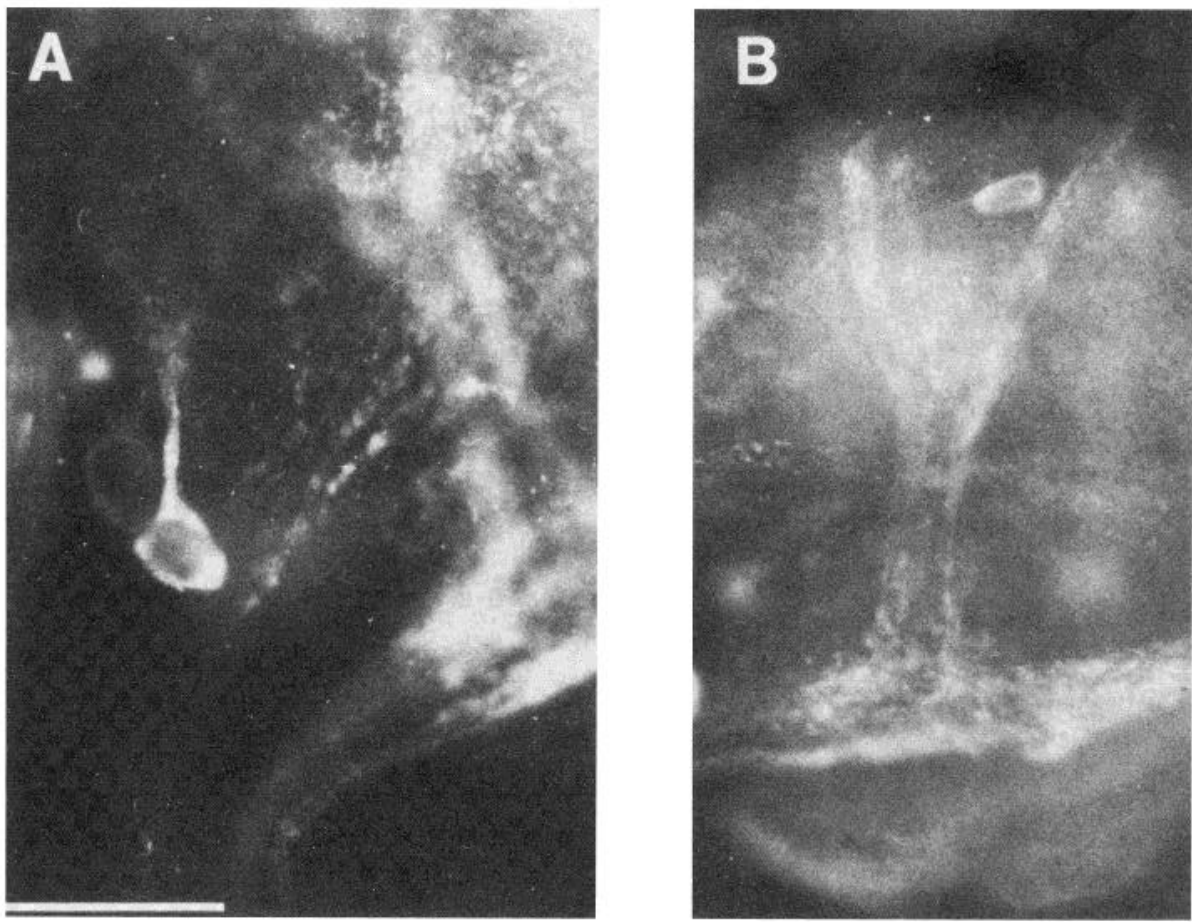

Figure 9. Immunoreactive structures of whole mounts of cerebral ganglion of a small juvenile $(A)$ and a large juvenile $(B)$. The top part of the field is rostral. $A$, Intensely stained iSCP ${ }_{B}$ large neuron in the left $E$ cluster. Also shown are iSCP fiber tracts and neuropil. $B$, Characteristic iSCP $\mathrm{P}_{\mathrm{B}}$ fiber tracts in a left hemiganglion. The intense tract of immunoreactive material in the lower part of the field runs from the commissure (left) into the pleural connective (right). The Y-shaped structure at the top of the field continues into the two large anterior nerves (upper labial and anterior tentacular). A medium-sized iSCP cell was always located at the plane of focus of the $Y$, within the two arms. Calibration bar $=50 \mu \mathrm{m}$.

Esophageal group. Each esophageal group of iSCP $\mathrm{CP}_{\mathrm{B}}$ cells always contained a pair of large, intensely stained neurons (Fig. 2). In several preparations, stained axons originating from these large neurons could be traced down the ipsilateral esophageal nerve (Fig. 2). Based on their size, location in the ganglion, and axon distribution these cells were identified as neurons B1 and B2 (Gardner, 1971). This conclusion is supported by immunocytological and biochemical studies of adult ganglia (see later under "Results"). Directly adjacent to $\mathrm{B} 1$ and $\mathrm{B} 2$ were two to four smaller iSCP $_{\mathrm{B}}$ neurons that also showed stained axons in the esophageal nerve (Fig. 3, A2 and B2).

Rostral group. The rostral group consisted of 15 to 25 neurons that uniformly showed intense staining (Fig. 3, A1 and B1). There was a moderate gradation in the size of these neurons: the largest cells in the group were closest to the buccal-buccal commissure whereas the smaller neurons were more lateral. One or two neurons could appear just outside the cluster (Fig. 3B1, right hemiganglion), but the great majority of these neurons were in direct contact, without non-iSCP $\mathrm{B}_{\mathrm{B}}$ neurons interposed. These cells appeared to give rise to axons that traveled into the buccal ganglion commissure, but the resolution was insufficient to trace individual axons to a given cell body. In one well stained preparation, the buccal ganglion commissure showed many immunoreactive varicosities (Fig. 3B1) The axons of these neurons also appeared to continue from the commissure into the radula nerve. In ganglia from the smallest animals, the neurons of this group were only slightly smaller than the other neurons (Fig. 3, B1 and B2). However, in the larger juvenile animals these neurons were considerably smaller than the other stained cells. In adult animals, the relative size of the rostral neurons had decreased still further.

Ventral group. The neurons in the ventral neuron group (Fig. 3 , $A 1$ and $B 1$, small arrows) showed more variable staining than did the other groups. In three ganglia these neurons stained lightly, whereas in two ganglia, these cells showed relatively intense stain ing. Furthermore, within a single ganglion, some of the scattered neurons clearly stained more intensely than others, but no spatial pattern of organization was evident. The stained ventral neurons are located in a region of the buccal ganglia previously shown to contain motor neurons (Cohen et al., 1978; Rosen et al., 1982).

\section{Adult Animals}

Localization of iSCP $_{\mathrm{B}}$ neurons in the buccal ganglia of adult animals ( 20 to $100 \mathrm{gm}$ body weight) was done on cryostat sections. 

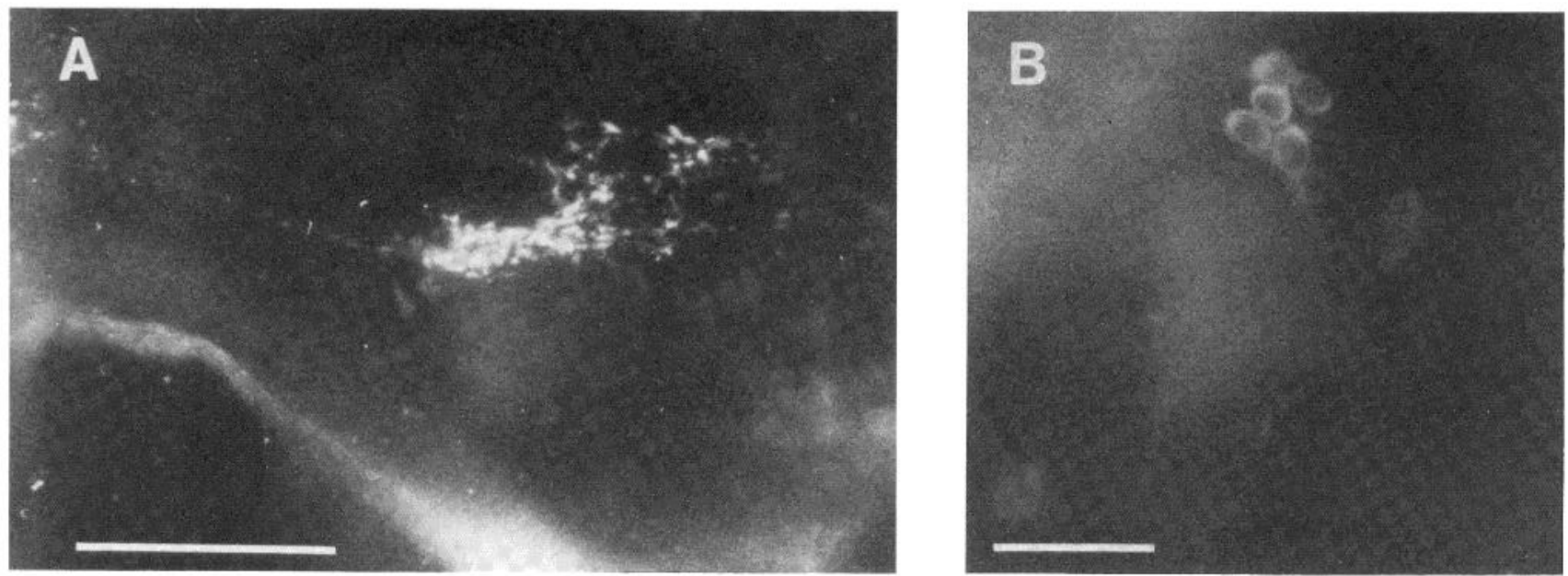

Figure 10. Immunoreactive structures of a whole mount of the cerebral ganglia from a medium-sized juvenile animal. The top part of the field is rostral. $A$, Right hemiganglion with a portion of the left hemiganglion. An iSCP $\mathrm{B}_{\mathrm{B}}$ tract running in the caudal part of the commissure is visible. The center of the field shows a characteristic neuropil with intense presumptive varicosities. The edge of the symmetrical cluster is visible in the left field. $B$, Small-cell cluster of rostral iSCP cells. Calibration bars, $50 \mu \mathrm{m}$.

The sections showed the same general pattern of iSCP $\mathrm{B}_{\mathrm{B}}$ staining as shown in the whole mounts of juvenile animals. The absolute size of all of the stained neurons was larger in the adult animals than in the juveniles. The neurons in the rostral cell group were smaller, relative to the size of B1 and B2 neurons in the adult animals, than in the juveniles (Fig. 4). The ratio of the mean maximum diameter of the iSCP small cells to that of the mean of B1 and B2 in three juvenile animals was $0.47 \pm 0.10$ (SEM). Measurements made in three complete series of sections from an adult animal gave a comparable ratio of $0.15 \pm 0.01$. A difference of this magnitude is unlikely to be an artifact caused by comparing neurons in sections to neurons in whole mount. Serial reconstruction was done in order to localize the rostral cell group in adult buccal ganglia. They were found in a narrow band on the dorsal edge of the rostral surface, just ventral to the esophageal nerve.

\section{Measurement of cardioactive substances in single neurons in the buccal ganglia}

Single neurons were identified visually and dissected from the buccal ganglia from large adult Aplysia (1 to $2 \mathrm{~kg}$ ). The lyophilized, crude extracts from these neurons were taken up in snail saline and tested for activity on isolated snail hearts. These preparations typically demonstrated a threshold response to the pulse application of $10 \mathrm{fmol}$ of $\mathrm{SCP}_{\mathrm{B}}$ or $200 \mathrm{fmol}$ of serotonin. The activity present in extracts of buccal neurons is unlikely to be due to serotonin for two reasons: (1) no serotonin-immunoreactive neurons are present in the buccal ganglia (Goldstein et al., 1984; Ono and McCaman, 1984), and (2) although the dissected buccal neuronal cell bodies are likely to be contaminated with some serotonergic fibers (Schwartz and Shkolnik, 1981; Ono and McCaman, 1984), the levels appear to be far below the lower sensitivity of the heart to serotonin.

Three hemiganglia, two left and one right, each from a different animal, were analyzed. About 20 large neurons and several clusters of small neurons were dissected from each hemiganglion. Two major groups of neurons which contained cardioactive substances were found in each ganglion. One group consisted of identified neurons $\mathrm{B} 1$ and $\mathrm{B} 2$ and up to five additional smaller unidentified neurons immediately surrounding these two large neurons. The activity present in $\mathrm{B} 1$ was equivalent to $8.9 \pm 2.7 \mathrm{pmol}$ and that in $\mathrm{B} 2$ was equivalent to $6.6+3.3 \mathrm{pmol}$ of a synthetic $\mathrm{SCP}_{\mathrm{B}}$ standard (mean $\pm \mathrm{SD} ; N=3$ ). The second major group of neurons containing cardioactive substances was found in the area of the ventral group, the region in which the large motor neurons which innervate buccal muscle are located. We selected the four largest neurons in this region and individually assayed them. Three of these neurons were always positive on the heart and one was negative. Unambiguous identification of these neurons can only be accomplished by characterizing their physiological properties.

The amount of cardioactive material in the large neurons of the ventral region was considerably more variable than that present in $\mathrm{B} 1$ and B2. For example, in the two largest positive neurons, in three preparations, the amount of cardioactivity present was $8 \%, 13 \%$, and $46 \%$ of the cardioactivity present in B1 and B2. As B1, B2, and the two largest ventral area neurons are similar in size, this suggests that the concentration of activity present in the ventral group cells ranges from roughly 0.1 to 0.5 of that in $\mathrm{B} 1$ and $\mathrm{B} 2$. In addition to the large neurons, several other intermediate-sized neurons (one to three, depending on the preparation) in the same region were positive on the bioassay. These neurons, although smaller than the large ventral neurons, were still considerably larger than cells in the rostral cell group.

\section{HPLC of B1, B2, and the large ventral neurons}

Measurement of cardioactivity of unprocessed neurons is insufficient, in itself, to determine whether the cardioactivity is associated with the presence of the SCPS. We therefore fractionated the contents of these neurons using RP-HPLC and measured SCPs by bioassay. Extracts of either B1 and B2 neurons or the four largest ventral neurons (one of which does not contain cardioactivity) were dissected and pooled from 25 animals and were chromatographed by RP-HPLC without carrier tissue (see below). The chromatographed fractions were dried and assayed for cardioactivity on the isolated snail heart. The results of one set of these experiments are shown in Figure 5. The activity profiles of each extract show two dominant peaks with the same retention times as those of $\mathrm{SCP}_{\mathrm{A}}$ and $\mathrm{SCP}_{\mathrm{B}}$. There are also two other peaks of activity, a small one and a larger broad peak with a retention time of 9 to $11 \mathrm{~min}$. We are currently investigating the properties of these two secondary peaks.

The results presented above do not distinguish whether the two SCPS are present in the same individual neuron or whether a neuron contains only one SCP and the presence of both SCPs in the extract is a consequence of the pooling procedure. To address this question, single B1 or B2 neurons were identified (see "Materials and Methods") and dissected from the buccal ganglia of large animals. They were separately added to heart carrier tissue, processed, and chromatographed by RP.HPLC. The results of one of these analyses are shown in Figure 6 , and they unequivocally demonstrate that both $\mathrm{SCP}_{\mathrm{A}}$ and $\mathrm{SCP}_{\mathrm{B}}$ are present in both individual $\mathrm{B} 1$ and $\mathrm{B} 2$ neurons. Thus, the two peptides coexist in single neurons. Although the total activity present in these neurons varied considerably, the ratio of the 

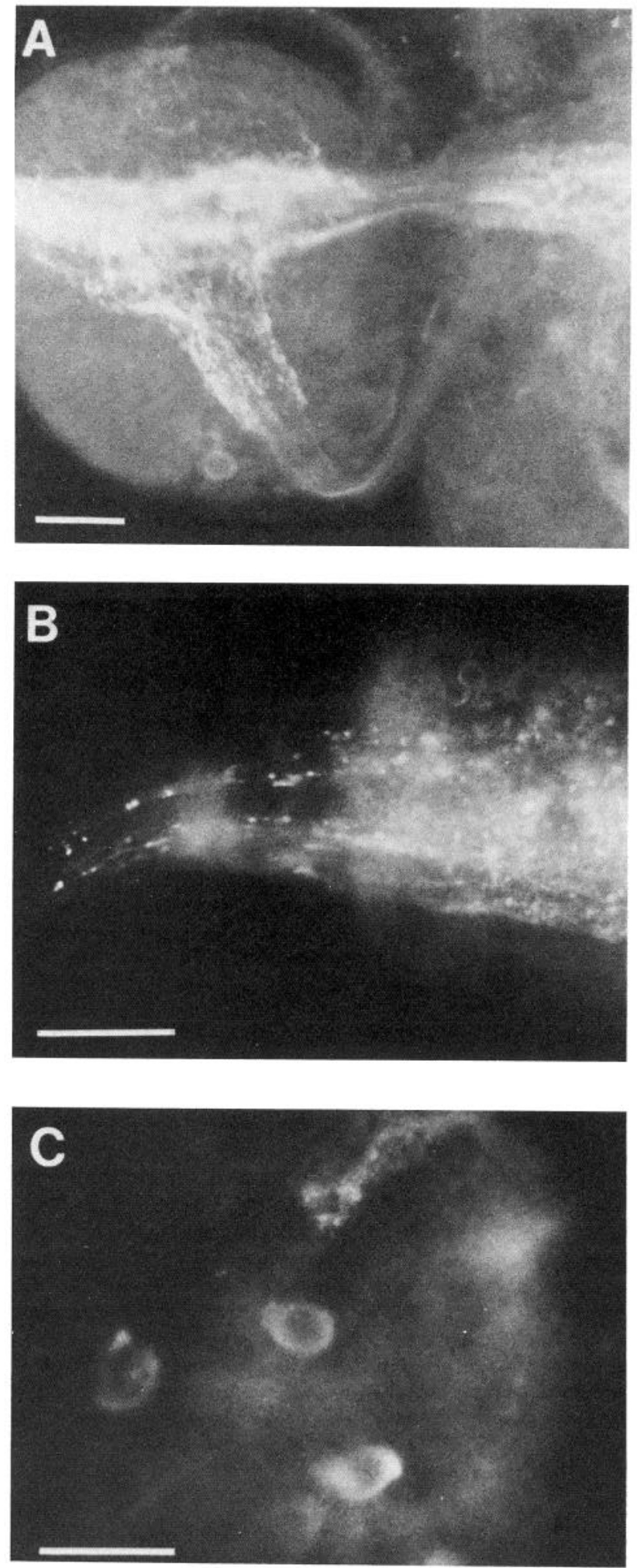

Figure 11. Immunoreactive structures of whole mounts of the pedal and pleural ganglia from medium-sized $(A)$ and small $(B$ and $C$ ) juvenile animals. $A$, Pleural ganglion showing characteristic ${ }_{S C} \mathrm{P}_{\mathrm{B}}$ fiber tracts and neuropil. The three arms correspond to the three input-output tracts of the ganglion: the cerebral pedal commissure and abdominal connectives. An iSCP cell body is visible in the lower part of the field. $B$. View of pedal commissure and medial edge of the pedal ganglion, showing intense iSCP fibers and presumptive varicosities. $C$. Pedal ganglion showing three iSCP neurons, and a region of presumptive varicosities. Calibration bars, $50 \mu \mathrm{m}$. activity of $\mathrm{SCP}_{\mathrm{A}}$ to that of $\mathrm{SCP}_{\mathrm{B}}$ was always similar in both neurons: $1.36 \pm 0.14$ (mean $\pm \mathrm{SE} ; N=7$ ) for $\mathrm{B} 1$ and $1.59 \pm 0.17(N=7)$ for B2. The portion of the ganglia that remained after the removal of $\mathrm{B} 1, \mathrm{~B} 2$, and the other small neurons in their cluster had a similar activity ratio, $1.35 \pm 0.06(N=6)$.

\section{Coexistence of CAT and the SCPS}

As part of a systematic survey of the neurotransmitters of identified neurons in the buccal ganglia (J. L. Cohen, K. R. Weiss, and I. Kupfermann, manuscript in preparation), we obtained evidence that numerous neurons in the buccal ganglion were cholinergic, based on the criteria that they contain CAT activity (Giller and Schwartz, 1971; Eisenstadt et al., 1973). We determined whether either B1 or $\mathrm{B} 2$ was capable of synthesizing acetylcholine (ACh) from radiolabeled choline. Individual B1 or B2 neurons were visually identified (see "Materials and Methods'). In a given ganglion, either one or the other cell was injected with $\left[{ }^{3} \mathrm{H}\right]$ choline and the conversion into $\mathrm{ACh}$ was determined. The fate of the injected $\left[{ }^{3} \mathrm{H}\right]$ choline in $\mathrm{B} 1$ and $\mathrm{B} 2$ is shown in Figure 7. The conversion of choline to ACh in B2 (44\%) is comparable to that observed in known cholinergic neurons, whereas that for $\mathrm{B} 1(2.2 \%)$ is in the range of that of known noncholinergic neurons (Giller and Schwartz, 1971; Eisenstadt et al., 1973; Cohen et al., 1978). These data raise the possibility that the SCPs and ACh are co-transmitters in B2.

\section{Immunocytological localization of $\mathrm{SCP}_{B}$ in the remainder of the CNS}

\section{Abdominal ganglion}

Five of five whole mounts of abdominal ganglia studied showed light staining of two characteristic small cells located deep in the left hemiganglion toward the dorsal surface (Fig. 8). Two preparations also had stained cells in the right caudal region toward the ventral surface. The abdominal ganglion also exhibited strong staining of fibers and varicosities in the neuropil (Fig. 8).

Stained cells were not observed in sections of adult ganglia. This may be due to the fact that the positive neurons stain lightly and are small and, therefore, may be missed in sections. Alternatively, the immunoreactive substances in the cells of the abdominal ganglia of juveniles may no longer be present in adult animals.

\section{Cerebral ganglia}

Staining of neurons in whole mounts of the cerebral ganglia appeared to be less constant than in the abdominal or buccal ganglia, but, nevertheless, certain cell groups regularly stained (Fig. 9). Of particular interest to us was the finding that two large neurons of the $\mathrm{E}$ cluster of the cerebral ganglion stained (Fig. 9A). One cell always stained strongly, whereas the other cell showed variability of staining and in two of five preparations was not observed. The $E$ cluster is made up of approximately 100 neurons including the identified histaminergic cell $\mathrm{C} 2$ and various of its synaptic follower cells, including a number of identified motoneurons (McCaman and Weinreich, 1982; Jahan-Parwar and Fredman, 1983; Chiel et al., 1982; H. J. Chiel, K. R. Weiss, and I. Kupfermann, unpublished observations). Pilot studies involving bioassays of individually dissected neurons from $E$ clusters from five animals indicated that almost all of the cardioactivity in each cluster was present in one or two neurons located near identified neuron $\mathrm{C} 2$. We are presently attempting to identify these neurons as unique individuals by their physiological properties. The cerebral ganglion also contained several groups of small and medium-sized immunoreactive neurons that appeared to be re-identifiable based on their size, general position, and relation to specific characteristic fiber tracts that showed $\mathrm{SCP}_{\mathrm{B}}$ staining (Figs. $9 B$ and $10 B$ ). The cerebral ganglion also contained an unusual neuropilar structure (Fig. 10A) which consisted of a highly localized collection of intense varicosities. In addition to this neuropil, the cerebral ganglion exhibited generalized staining of fiber tracts and central neuropil, similar to that shown by the other ganglia. 

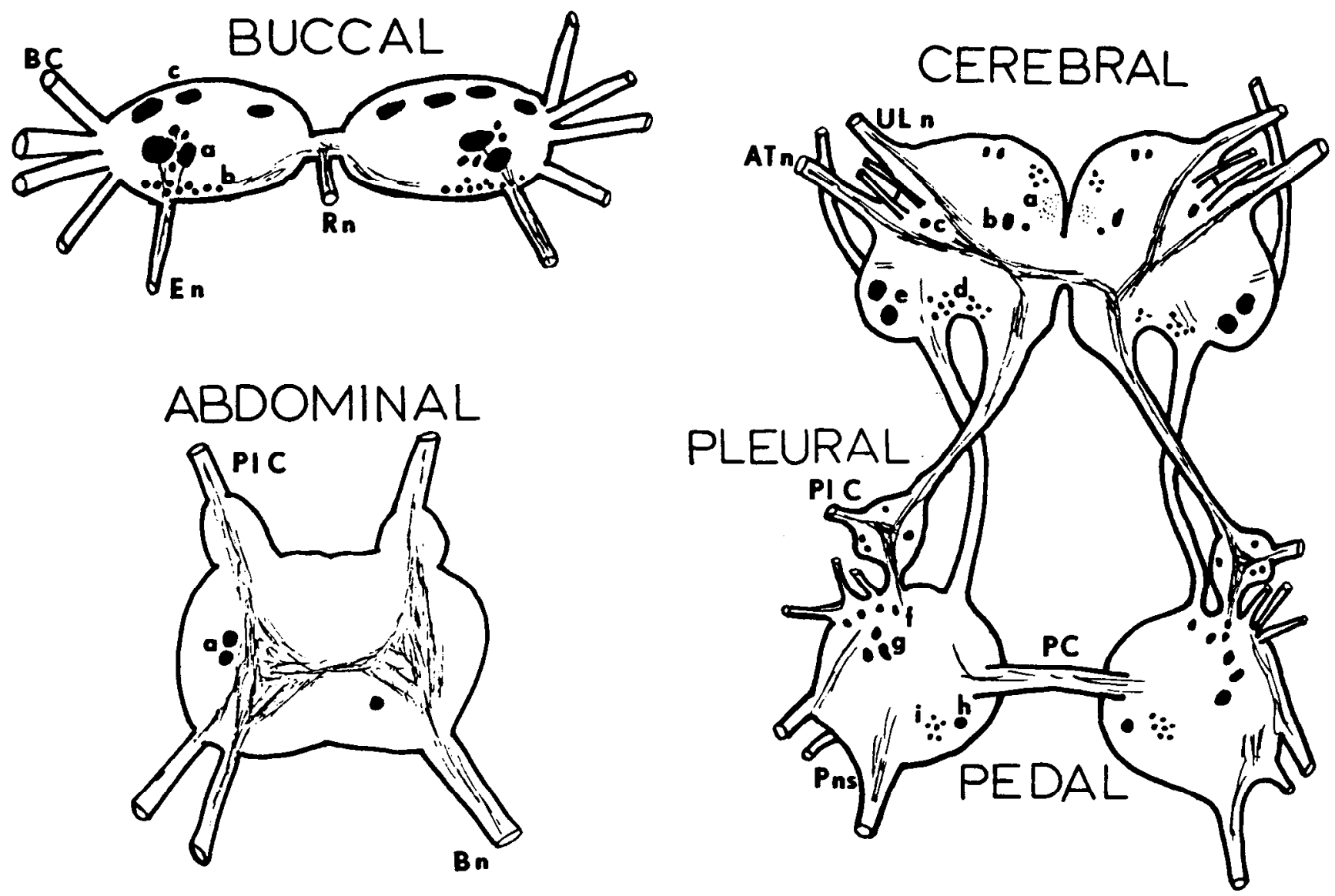

Figure 12. Schematic representation of cells exhibiting $\mathrm{SCP}_{\mathrm{B}}$ immunoreactivity in whole mounts of the central ganglia of $A p / y s i a$. Prominent iSCP $\mathrm{P}_{\mathrm{B}}$ fibers and varicosities are also indicated. Cells or cell clusters that were identifiable in every well stained preparation are indicated by lower case letters. The cells without letters are identified in more than one preparation but could not be unequivocally located in all cases. The buccal ganglion (upper left) shows three groups of symmetrical cells. The group labeled a consists of identified cells B1, B2, and associated cells, and is located on the caudal surface. Group $b$ consists of smaller cells located on the rostral surface. Group $c$ consists of scattered large and medium-sized cells located on the rostral and caudal surfaces, toward the ventral edge of the ganglion. The abdominal ganglion (lower left) had only one pair of regularly staining cells, labeled a, located on the dorsal surface of the left hemiganglion. In the cerebral ganglion (upper right) a cluster of strongly immunoreactive presumptive varicosities is located in the region labeled $a$. Cell $b$ is located ventrally, toward the midline. Cell $c$ is located dorsally, between fiber tracts streaming into the anterior tentacular and upper labial nerves. Group d consists of two clusters of small cells located dorsally. Group e is ventral, and consists of one large, regularly staining neuron and another, less regularly staining neuron. In the pleural ganglion (middle right) none of the stained cells of the pleural ganglion could be regularly identified. In the pedal ganglion (lower right) group $f$ consists of medium-sized cells, located dorsally, near the pedal-pleural connective. Group $g$ consists of larger cells located ventrally and toward the center of each hemiganglion. Cell $h$ is a relatively large cell located medially, on the dorsal surface. Group $i$ consists of small cells toward the dorsal surface. Note that the size of one ganglion relative to another is not drawn to scale in the figure. ATn, anterior tentacular nerve; $B C$, buccal-cerebral connective; $B n$, branchial nerve; $E n$, esophageal nerve; $P n s$, pedal nerves; $P I C$, pleural-abdominal connective; $P C$, pleural commissure; $R n$, radula nerve; UL $n$, upper labial nerve.

\section{Pedal-pleural ganglia}

Whole mounts of pleural ganglia showed intense staining of neuropil, nerves, and connectives (Fig. $11 \mathrm{~A}$ ), but only occasional stained cells were observed (Fig. 12), many of which could not be located from preparation to preparation. In sectioned material from five animals, no stained cells in the pleural ganglion were observed. The pedal ganglia of whole mounts (Fig. 11, B and $C$ ) and of sectioned material showed staining of 10 to 15 neurons, none of which were re-identifiable using visual criteria alone. The neuropil of the pedal ganglia was also strongly stained.

\section{Discussion}

Our biochemical results indicate that $\mathrm{SCP}_{\mathrm{A}}$ and $\mathrm{SCP}_{\mathrm{B}}$ are found throughout the nervous system of Aplysia. This conclusion is supported by our studies utilizing immunocytology, which revealed $\mathrm{SCP}_{\mathrm{B}}$-immunoreactive cell bodies, fibers, and varicosities in all of the major central ganglia of the animal (Fig. 12). Our controls are consistent with the interpretation that we are staining for $\mathrm{SCP}_{\mathrm{B}}$.
However, no immunocytochemical control or even set of controls can definitively identify an immunoreactive substance (Swaab et al., 1977). Indeed, we have recently found that the carboxy-terminal amide and seven amino acid residues of $\mathrm{SCP}_{\mathrm{B}}$ are identical to those of SCPA (Lloyd et al., 1984b), and it is therefore likely that our polyclonal antibodies to $\mathrm{SCP}_{B}$ are detecting $S C P_{A}$ as well. From our HPLC analyses it appears that $\mathrm{SCP}_{\mathrm{A}}$ and $\mathrm{SCP}_{\mathrm{B}}$ always coexisted in the neurons and tissues we examined, a finding that is consistent with the recent observation that the two peptides are likely to be processed from a single precursor (Mahon et al., 1985).

To strengthen our conclusion regarding the localization of $\mathrm{SCP}_{\mathrm{B}}$, we have combined immunocytochemistry with biochemical characterization of selected neurons. Characterization of identified buccal neurons $\mathrm{B} 1$ and $\mathrm{B} 2$ and clusters of buccal ventral neurons revealed that they contain genuine $\mathrm{SCP}_{\mathrm{A}}$ and $\mathrm{SCP}_{\mathrm{B}}$. The techniques we have used could also be applied to other central neurons. However, aside from a few very large neurons such as B1 and B2, most neurons in the buccal ganglia of Aplysia cannot be identified solely on the basis of size and position. Therefore, definitive determination of the iSCP 
cells will require identification by means of physiological techniques, followed by cell marking and immunocytochemical or biochemical characterization (Ono and McCaman, 1980).

Possible coexistence of $A C h$ and $S C P_{A}$ and $S C P_{R}$. Our data suggest that, whereas both identified cells $B 1$ and $B 2$ contain $S C P_{A}$ and $\mathrm{SCP}_{\mathrm{B}}$, only neuron $\mathrm{B} 2$ contains CAT activity. Additional experiments will be needed to definitively establish that $B 2$ utilizes both SCPs and ACh as transmitters, but previous studies in Aplysia indicate that cholinergic neurons have CAT activity, whereas noncholinergic neurons never have significant CAT activity (Giller and Schwartz, 1971; Eisenstadt et al., 1973; Cohen et al., 1978). B1 and B2 may prove advantageous for cellular studies of multiple transmitters since these neurons are very large, simple to identify, and, although strikingly similar in many respects, differ in ACh-synthesiz ing capacity. The work of Lloyd et al. (1981) suggests that neuron B11 in the buccal ganglion of Tritonia also contains SCP and ACh. Indeed, the general characteristics of $\mathrm{B} 11$ suggest that it may be homologous to B2 of Aplysia.

Distribution of $i S C P_{B}$ and $S C P_{B}$. iSCP $P_{B}$ fibers and neurons were observed in all central ganglia of $A p l y s i a$, and this is consistent with the distribution of $\mathrm{SCP}_{\mathrm{B}}$ and $\mathrm{SCP}_{\mathrm{A}}$ determined by HPLC and bioassay. The highest content of $S C P_{B}$ and $S C P_{A}$ was found in the buccal ganglion, which exhibited the greatest number and most intense staining of neurons. This finding suggests that the SCPS may have an important role in feeding behavior. Two of the iSCP neurons, B1 and $B 2$, send axons down the esophageal nerve and innervate the esophagus and more posterior portions of the gut, which also contain the two peptides (Lloyd et al., 1984b). It is likely that some of the other immunoreactive neurons innervate buccal muscles, since many of these neurons are in a region of the ganglion that contains buccal muscle motor neurons. Furthermore, the buccal muscles contain significant amounts of the SCPS and at least one muscle, the accessory radula closer (ARC), exhibits iSCP $\mathrm{P}_{\mathrm{B}}$ staining of varicosities (Lloyd et al., 1984a). Since physiological studies of the ARC muscle indicate that $\mathrm{SCP}_{\mathrm{B}}$ potentiates buccal contractions without, in itself, eliciting contractions, it appears likely that $\mathrm{SCP}_{B}$ acts as a modulator of buccal muscles (Lloyd et al., 1984a). Thus, SCP $\mathrm{B}$ might function in parallel with serotonin, which previously has been shown to modulate buccal muscle contractions (Weiss et al., 1978).

In ganglia other than the buccal, $\mathrm{SCP}_{\mathrm{B}}$ appears to be present primarily in fiber tracts and varicosities. In addition, it appears that immunoreactive buccal neurons do not send fibers out of the cerebral-buccal connective to provide the source of immunoreactivity in the other central ganglia. Taken together, these findings raise the possibility that a major source of the SCPS in the neuropil is from sensory neurons which have their cell bodies located outside the central ganglia. Many of the SCP $_{B}$ neurons in nonbuccal ganglia showed only very light staining, indicating either that they had a relatively low concentration of $\mathrm{SCP}_{8}$ or that they contain some other substance that cross-reacts with our $\mathrm{SCP}_{\mathrm{B}}$ antisera but with relatively low affinity. However, experiments on lightly staining cells in buccal ganglia showed that these cells simply contain lower levels of the SCPS

The physiological actions of $\mathrm{SCP}_{\mathrm{B}}$ and serotonin are often strikingly similar (Lloyd, 1982). In addition to their similar actions on the heart beat amplitude and rate (Lloyd, 1980a), these substances modulate extrinsic (Lloyd, 1980b) and intrinsic (Lloyd et al., 1984b) buccal muscle responses and enhance the synaptic potentials produced by sensory neurons in the abdominal ganglia (Abrams et al., 1984). Given the similarity of these actions, it is interesting that our immunocytological studies indicate that $\mathrm{SCP}_{\mathrm{B}}$ is not present in perisomatic baskets that are characteristic of serotonergic (Goldstein et al., 1984; Ono and McCaman, 1984; Kistler et al., 1985) as well as certain peptidergic innervation in Aplysia (Chiu and Strumwasser. 1981; McAllister et al., 1983). These baskets are made up of a network of fibers and varicosities surrounding neuronal cell bodies. This difference in the distribution of $\mathrm{SCP}_{\mathrm{B}}$ and serolonin termirials suggests that, although they often have similar actions, significant differences in their physiological actions may remain to be uncovered.

Previous studies have shown that a single conventional transmitter, serotonin, may be involved in two types of behavioral plasticityone involving a change in motivational state (Weiss et al., 1982), and another involving learning (Kandel and Schwartz, 1982) in Aplysia. The findings of Lloyd et al. (1984a) and Abrams et al. (1984) suggest that the SCPS are also involved in the same two forms of behavioral plasticity. In addition, the wide distribution of iSCP within the synaptic regions of all the central ganglia suggests that the SCPS are also involved in mediating other behaviors

\section{References}

Abrams, T. W., V. F. Castellucci, J. S. Camardo, E. R. Kandel, and P. E. Lloyd (1984) Two endogenous neuropeptides modulate the gill and siphon withdrawal reflex in Aplysia by means of presynaptic facilitation involving cyclic AMP-dependent closure of the serotonin-sensitive $S$ potassium channel. Proc. Natl. Acad. Sci. U. S. A. 81: 7956-7960

Adams, M. E., and M. O'Shea (1983) Peptide co-transmitter at a neuromuscular junction. Science 221: 286-289.

Bennett, H. P. J., C. A. Brown, and S. Solomon (1980) The use of perfluorinated carboxylic acids in the reverse-phase HPLC of peptides. J. Liquid Chromatogr. 3: 1353-1365

Bishop, C. A., and M. O'Shea (1982) Neuropeptide proctolin (H.Arg-Tyr-LeuPro-Thr-OH): Immunocytochemical mapping of neurons in the central nervous system of the cockroach. J. Comp. Neurol. 207: 223-228.

Chiel, H. J., K. R. Weiss, and I. Kupfermann (1982) An identified histaminergic neuron modulates lip and mouth feeding movements in Aplysia. Soc. Neurosci. Abstr. 8: 823

Chiu, A. Y., and F. Strumwasser (1981) An immunocytochemical study of the neuropeptidergic bag cells of Aplysia. J. Neurosci. 7: 812-826.

Cohen, J. L., K. R. Weiss, and I. Kuptermann (1978) Motor control of bucca muscles in Aplysia. J. Neurophysiol. 41: 157-180.

Coons, A. H. (1958) Fluorescent antibody methods. In General Cytochemical Methods, J. F. Danielli, ed., pp. 339-422, Academic Press, Inc., New York.

Cottrell, G. A., L. P. C. Schot, and G. J. Dockray (1983) Identification and probable role of a single neuron containing the neuropeptide Helix FMRF. amide. Nature 304: 638-640.

Eckert, M., H. Agricola, and H. Penzlin (1981) Immunocytochemical identifi cation of proctolin-like immunoreactivity in the terminal ganglia and hindgut of the cockroach Periplaneta americana (L.). Cell Tissue Res. 217 633-645.

Eisenstadt, M., J. E. Goldman, E. R. Kandel, H. Koike, J. Koester, and J. H. Schwartz (1973) Intrasomatic injection of radioactive precursors for studying transmitter synthesis in identified neurons of Aplysia californica. Proc. Natl. Acad. Sci. U. S. A. 70: 3371-3375

El-Salhy, M., S. Falkmer, K. J. Kramer, and R. D. Speins (1983) Immunohis tochemical investigations of neuropeptides in the brain, corpora cardiaca and corpora allata of an adult lepidopteran insect. Manduca sexta (L). Cell Tissue Res. 232: 295-317.

Gardner, D. (1971) Bilateral symmetry and interneuronal organization in the buccal ganglia of Aplysia. Science 173: 550-553.

Giller, E., and J. H. Schwartz (1971) Choline acetyltransferase in identified neurons of abdominal ganglion of Aplysia californica. J. Neurophysiol. 34: 93-107

Goldstein, R., H. B. Kistier, Jr., H. W. M. Steinbusch, and J. H. Schwartz (1984) Distribution of serotonin-immunoreactivity in juvenile Aplysia. Neuroscience 11: 535-547.

Greenberg, M. J., S. D. Painter, K. E. Doble, G. T. Nagle, D. A. Price, and H. K. Lehman (1983) The molluscan neurosecretory peptide FMRFamide Comparative pharmacology and relationship to enkephalins. Fed. Proc. 42: 82-86.

Jahan-Parwar. B., and S. M. Fredman (1983) Control of extrinsic feeding muscles in Aplysia. J. Neurophysiol. 49: 1481-1503.

Jan, L. Y., and Y. N. Jan (1982) Peptidergic transmission in the sympathetic ganglia of the frog. J. Physiol. (Lond.) 327: 219-246.

Kandel, E. R., and J. H. Schwartz (1982) Molecular biology of learning: Modulation of transmitter release. Science 218: 433-443.

Kistler, H. B., Jr., R. D. Hawkins, J. Koester, H. W. M. Steinbusch, E. R. Kandel, and J. H. Schwartz (1985) Distribution of serotonin-immunoreactive cell bodies and processes in the abdominal ganglion of mature Aplysia. J. Neurosci. 5: 72-80.

Koike, H., E. R. Kandel, and J. H. Schwartz (1974) Synaptic release of 
radioactivity after intrasomatic injection of choline $-{ }^{3} \mathrm{H}$ into an identified cholinergic interneuron in abdominal ganglion of Aplysia californica. J. Neurophysiol. 37: 815-827.

Kreiner, T., J. B. Rothbard, G. K. Schoolnik, and R. H. Scheller (1984) Antibodies to synthetic peptides defined by CDNA cloning reveal a network of peptidergic neurons in Aplysia. J. Neurosci. 4: 2581-2589.

Krieger, D. T. (1983) Brain Peptides: What, where, and why? Science 222: 975-985.

Kupfermann, I. (1974) Dissociation of the appetitive and consumatory phases of feeding behavior in Aolysia: A lesion study. Behav. Biol. 10: 89-97.

Lloyd, P. E. (1978) Distribution and molecular characteristics of cardioactive peptides in the snail, Helix aspersa. J. Comp. Physiol. 128A: 269-276.

Lloyd, P. E. (1980a) Biochemical and pharmacological analyses of endogenous cardioactive peptides in the snail, Helix aspersa. J. Comp. Physiol. 138A: 265-270.

Lloyd, P. E. (1980b) Modulation of neuromuscular activity by 5-hydroxytryptamine and endogenous peptides in the snail, Helix aspersa. J. Comp. Physiol. 139A: 333-339.

Lloyd, P. E. (1982) Cardioactive neuropeptides in gastropods. Fed. Proc. 41: 2948-2952.

Lloyd, P. E., B. Masinovsky, R. E. McCaman, and A. O. D. Willows (1981) Coexistence of a neuropeptide and acetylcholine in an identified molluscan neuron. Soc. Neurosci. Abstr. 7: 637.

Lloyd, P. E., I. Kuptermann, and K. R. Weiss (1984a) Evidence for parallel actions of a molluscan neuropeptide $\left(\mathrm{SCP}_{\mathrm{B}}\right)$ and serotonin in mediating arousal in Aplysia. Proc. Natl. Acad. Sci. U. S. A. 81: 2934-2937.

Lloyd. P. E. I. Kupfermann, and K. R. Weiss (1984b) Sequence and neuronal localization of a newly characterized neuropeptide in Aplysia. Soc. Neurosci. Abstr. 10: 153

Lloyd, P. E., I. Kupfermann, and K. R. Weiss (1985) Two endogenous peptides (the SCPS) cause a cAMP-mediated stimulation of cardiac activity in Aplysia. J. Comp. Physiol., in press.

Lundberg. J. M. (1981) Evidence for co-existence of VIP and acetylcholine in neurons of cat exocrine glands. Act Physiol. Scand. Suppl. 496: 1-57.

Mahon, A. C., P. E. Lloyd, K. R. Weiss, I. Kupfermann, and R. H. Scheller (1985) The small cardioactive peptides $A$ and $B$ of Aplysia are derived from a common precursor molecule. Proc. Natl. Acad. Sci. U. S. A., in press.

McAllister, L. B., R. H. Scheller, E. R. Kandel, and R. Axel (1983) In situ hybridization to study origin and fate of identified neurons. Science 222 : $800-808$
McCaman, R. E., and D. Weinreich (1982) On the nature of histaminemediated slow hyperpolarizing synaptic potentials in identified molluscan neurons. J. Physiol. (Lond.) 328: 485-506.

Morris, H. R., M. Panico, A. Karplus, P. E. Lloyd, and B. Riniker (1982) Elucidation by FAB.MS of the structure of a new cardioactive peptide from Aplysia. Nature 300: 643-645

Ono, J. K., and R. E. McCaman (1980) Identification of additional histaminergic neurons in Aplysia: Improvement of single cell isolation techniques for in tandem physiological and chemical studies. Neuroscience 5: 835840.

Ono, J. K., and R. E. McCaman (1984) Immunocytochemical localization and direct assays of serotonin-containing neurons in Aplysia. Neuroscience 11: $549-560$.

Osborne, N. N., A. C. Cuello, and G. J. Dockray (1982) Substance P and cholecystokinin-like peptides in Helix neurons and cholecystokinin and serotonin in a giant neuron. Science 216: 409-411.

Rosen, S. C., K. R. Weiss, J. L. Cohen, and I. Kupfermann (1982) Interganglionic cerebral-buccal mechanoafferents of Aplysia: Receplive fields and synaptic connections to different classes of neurons involved in feeding behavior. J. Neurophysiol. 48: 271-288.

Schot, L. P. C., H. H. Boer, D. F. Swaab, and N. S. Van (1981) Immunochemical demonstration of peptidergic neurons in the central nervous system of the pond snail Lymnaea stagnalis with antisera raised to biologically active peptides of vertebrates. Cell Tissue Res. 216: 273-291.

Schwartz, J. H., and L. J. Shkolnik (1981) The giant serotonergic neuron of Aplysia: A multi-targeted nerve cell. J. Neurosci 1: 606-619.

Siwicki, K. K., and E. A. Kravitz (1983) Proctolin in lobsters: General distribution and co-localization with serotonin. Soc. Neurosci. Abstr. 9: 313.

Swabb, D. F., C. W. Pool, and F. W. Van Leeuwen (1977) Can specificity ever be proved in immunocytochemical staining? J. Histochem. Cytochem. 5: 388-391.

Vigna, S. R., J. L. M. Morgan, and T. M. Thomas (1984) Localization and characterization of gastrin/cholecystokinin-like immunoreactivity in the central nervous system of Aplysia californica. J. Neurosci. 4: 1370-1377.

Weiss, K. R., J. L. Cohen, and I. Kupfermann (1978) Modulatory control of buccal musculature by a serotonergic neuron (metacerebral cell) in Aplysia. J. Neurophysiol. 41: 181-203.

Weiss, K. R., U. T. Koch, J. Koester, S. C. Rosen, and I. Kupfermann (1982) The role of arousal in modulating feeding behavior of Aplysia: Neural and behavioral studies In The Neural Basis of Feeding and Reward, B. G. Hoebel and D. Novin, eds., pp. 25-57, Haer Institute, Brunswick, ME 